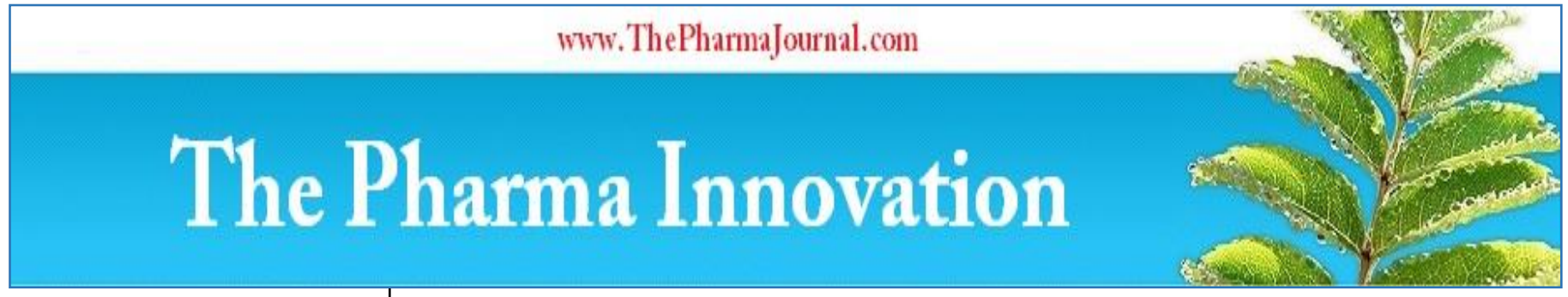

ISSN (E): 2277 - 7695

ISSN (P): 2349-8242

NAAS Rating: $\mathbf{5 . 0 3}$

TPI 2020; 9(7): 180-185

(C) $2020 \mathrm{TPI}$

www.thepharmajournal.com

Received: 10-05-2020

Accepted: 12-06-2020

\section{Ram Chander}

M.V.Sc. Scholar, Department of Clinical Veterinary Medicine,

Ethics \& Jurisprudence College of Veterinary and Animal

Science Rajasthan University of

Veterinary and Animal Sciences,

Bikaner, Rajasthan, India

\section{Sunita Choudhary}

Assi. Professor, Department of Clinical Veterinary Medicine,

Ethics \& Jurisprudence College of Veterinary and Animal

Science Rajasthan University of Veterinary and Animal Sciences, Bikaner, Rajasthan, India

\section{AP Singh}

Professor \& Head, Department of Clinical Veterinary Medicine, Ethics \& Jurisprudence College of Veterinary and Animal

Science Rajasthan University of Veterinary and Animal Sciences, Bikaner, Rajasthan, India

\section{Anju Chahar}

Professor \& Head, Dept. of

Epidemiology and Preventive

Veterinary Medicine College of

Veterinary and Animal Science

Rajasthan University of

Veterinary and Animal Sciences,

Bikaner, Rajasthan, India

\section{SK Koli}

M.V.Sc. Scholar, Department of Clinical Veterinary Medicine,

Ethics \& Jurisprudence College of Veterinary and Animal Science Rajasthan University of Veterinary and Animal Sciences, Bikaner, Rajasthan, India

\section{Corresponding Author:}

\section{Ram Chande}

M.V.Sc. Scholar, Department of Clinical Veterinary Medicine, Ethics \& Jurisprudence College of Veterinary and Animal Science Rajasthan University of Veterinary and Animal Sciences, Bikaner, Rajasthan, India

\section{Prevalence of canine demodicosis in Bikaner, Rajasthan}

\author{
Ram Chander, Sunita Choudhary, AP Singh, Anju Chahar and SK Koli
}

DOI: https://doi.org/10.22271/tpi.2020.v9.i7c.4855

\begin{abstract}
Canine demodicosis caused by ectoparasitic mites of the genus Demodex is a major and common ectoparasitic disease of dogs. The present study was conducted to determine the prevalence of Demodex infection in pet dogs. During the period under study from September 2018 to February 2019, a total of 774 dogs were presented at Veterinary Clinical Complex, College of Veterinary and Animal Science, Bikaner, Rajasthan. Out of these 774 dogs, $240(31 \%)$ dogs were having dermatological problem in which 25 dogs were positive for demodicosis (10.42\%). Out of these 25 dogs, 19 were affected with generalized demodicosis (76\% of demodicosis/ $7.91 \%$ of total dermatological cases) and 6 were affected with localized demodicosis (24\% of demodicosis/ $2.5 \%$ of total dermatological cases). The prevalence in female dogs (68\%) was higher than that in male dogs $(32 \%)$. In the present study, the highest prevalence of canine demodicosis was recorded in dogs aged up to 2 years (72\%) followed by $12 \%$ in 2 to 4 years and $16 \%$ in $>4$ years dogs. Out of 25 dogs breed-wise prevalence of canine demodicosis in the present study was found to be higher in Pug 12(48\%), followed by mongrel 6(24\%), Labrador 4(16\%), German shepherd 2(8\%), Dachshund 1(4\%).
\end{abstract}

Keywords: Bikaner, canine demodicosis, Demodex infection, prevalence

\section{Introduction}

Skin problems are one of the most common problems affecting dogs, of which those caused by ectoparasites like mites, fleas ticks and lice contributes a larger share. Demodectic mange is a very common ectoparasitic infestation, caused by Demodex canis and considered as parasites that can act as opportunistic pathogens in certain circumstances ${ }^{[1]}$

Canine demodicosis is categorized as localized and generalized according to the area of skin covered by the disease. Localized demodicosis occurs most commonly in young dogs of less than one year of age, and spontaneous remission occurs in most patients ${ }^{[2]}$.

Prevalence of canine demodicosis was unknown till now in Bikaner (Rajasthan), so the present study was taken up to study prevalence of demodecosis in canine age wise, gender wise, and breed was done.

\section{Materials and methods}

The proposed research work was carried out during the period under study in cases presented with dermatological problems at Veterinary Clinical Complex (VCC), College of Veterinary and Animal Science, Bikaner from September 2018 to February 2019.

\section{Animals}

The criteria for including dogs were history of pruriginous dermatitis and lesions characterised by erythema, papules, pustule, epidermal collarettes, crusts, alopecia, lichenification and hyperpigmentation. All the cases screened for dermatological disorders were clinically examined followed by skin scrapping and bacterial culture was done.

\section{Anamnesis (History taking)}

In the present study a complete history including age, gender, breed, hair coat, diet, deworming, seasonal occurence of disease, origin of hair loss on body, duration of disease, intensity and frequency of itching if present occurence of same disease in other dog of same kennel if any, previous investigation and therapy, any disease or lesion in member of the family of owners, use of disinfectant for cleaning floor and any other relevant information were collected from the dog owners which was recorded in the case history performa. 


\section{Analysis of prevalence}

The prevalence of demodicosis was calculated among the total number of dermatological cases screened. The prevalence was further analyzed in relation to age, gender and breed.

\section{Clinical examination}

Cases showing dermatological lesions like alopecia, folliculitis, pustules, erythema, scales, hyper pigmentation and lichenification on clinical examination was suspected for demodicosis, selected for further examination.

\section{Results and discussion}

The present study was conducted to investigate prevalence of canine demodicosis in relation to age, gender and breed.

\section{Prevalence of canine demodicosis}

During the study period of 6 months, a total of 774 dogs were presented at Veterinary Clinical Complex, College of Veterinary and Animal Science, Bikaner, Rajasthan. Out of these 774 dogs, 240 (31\%) dogs were having dermatological problem in which 25 dogs were positive for demodicosis $(10.42 \%)$. Out of these $25 \mathrm{dogs}, 19$ were affected with generalized demodicosis ( $76 \%$ of demodicosis/ $7.91 \%$ of total dermatological cases) and 6 were affected with localized demodicosis (24\% of demodicosis/ $2.5 \%$ of total dermatological cases $)^{[3,4,5]}$. (Table 1$)$

Table 1: Prevalence of canine demodicosis

\begin{tabular}{|c|c|c|}
\hline $\begin{array}{c}\text { Number having dermatological } \\
\text { disorders }\end{array}$ & $\begin{array}{c}\text { Number of cases positive for demodicosis out of } \\
\mathbf{2 4 0}\end{array}$ & $\begin{array}{c}\text { Prevalence of canine demodicosis } \\
(\boldsymbol{\%})\end{array}$ \\
\hline 240 & 25 & 10.42 \\
\hline
\end{tabular}

\section{Age wise prevalence of canine demodicosis}

The age-wise prevalence of canine demodicosis is represented in Table 2 and Figure 2. In the present study, the highest prevalence of canine demodicosis was recorded in dogs aged up to 2 years (72\%) followed by $12 \%$ in 2 to 4 years and $16 \%$ in $>4$ years dogs ${ }^{[6,7,8]}$. (Table 2 and Figure 1) They also observed that canine demodicosis occured in dogs less than 18 months of age and adult dogs developed the disease less frequently.

Higher prevalence of demodicosis in younger age group may be due to the fact that the puppies acquire the infection during the first few days of life while suckling milk from mother. During the puberty the sebaceous glands are stimulated by the sex hormones and the mites get an opportunity to grow and multiply since they are sebophilic ${ }^{[9,10]}$.

In young animals, endoparasiticism, malnutrition and debilitation may lead to an immunocompromized state that favours mite proliferation and development of skin disease [11].

Table 2: Age wise prevalence of canine demodicosis $(n=25)$

\begin{tabular}{|c|c|c|c|}
\hline S. No. & Age groups & Number affected & Percentage (\%) \\
\hline 1 & Up to 2 years & 18 & 72 \\
\hline 2 & $2-4$ years & 3 & 12 \\
\hline 3 & $>$ 4 years & 4 & 16 \\
\hline \multicolumn{2}{|c|}{ Total } & 25 & 100 \\
\hline
\end{tabular}

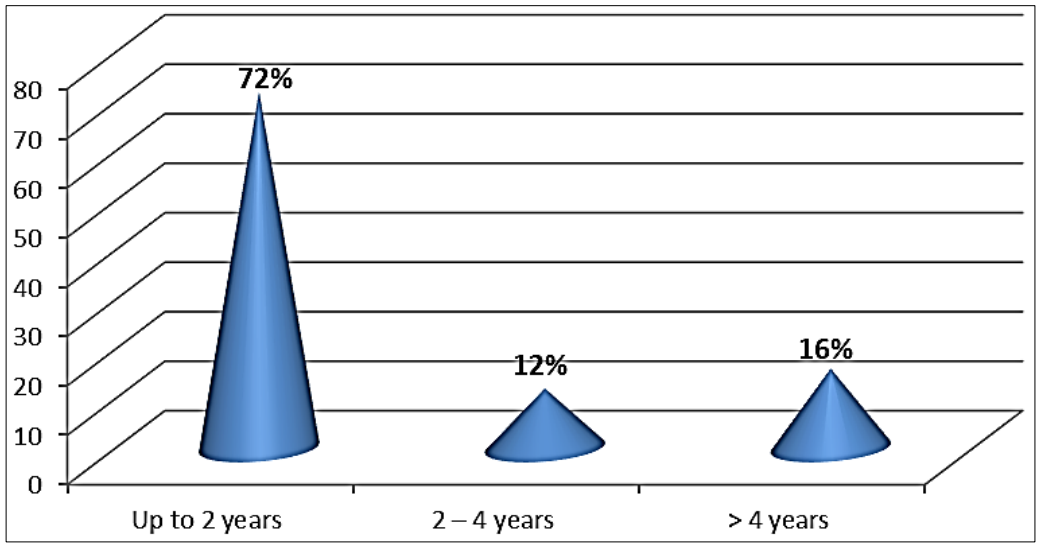

Fig 1: Age wise prevalence of canine demodicosis $(n=25)$

\section{Gender wise prevalence of canine demodicosis}

In the present study, out of $25 \mathrm{dogs}$ positive for canine demodicosis, 17 were female dog and 8 were male dog, showing high prevalence $68 \%$ in female dog compared to male dog showing 32\% prevalence (Table 3 and Figure 2).

In the present study, higher incidence of demodicosis in female dogs might be attributed due to some predisposing factors like puberty, estrus, pregnancy, parturition and lactation etc. ${ }^{[12,13,10]}$

Table 3: Gender wise prevalence of canine demodicosis $(n=25)$

\begin{tabular}{|c|c|c|}
\hline Gender & Number affected & Percentage (\%) \\
\hline Female & 17 & 68 \\
\hline Male & 8 & 32 \\
\hline Total & 25 & 100 \\
\hline
\end{tabular}




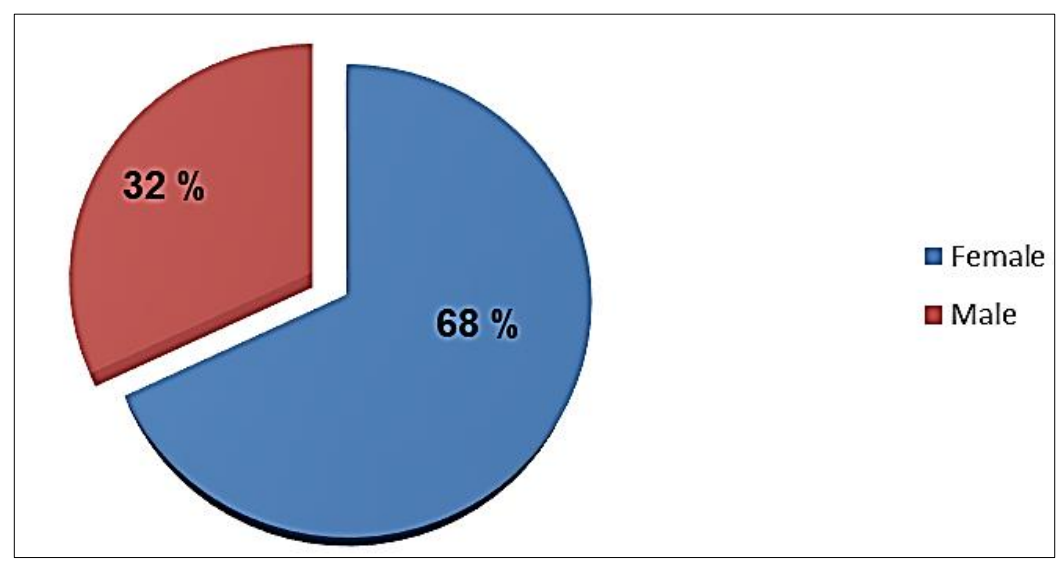

Fig 2: Gender wise prevalence of canine demodicosis $(n=25)$

\section{Breed wise prevalence of canine demodicosis}

Out of 25 dogs breed-wise prevalence of canine demodicosis in the present study was found to be higher in Pug 12(48\%), followed by mongrel 6(24\%), Labrador 4(16\%), German shepherd 2(8\%), Dachshund 1(4\%). (Table 4 and Figure 3) Similar observation were recorded by Solanki et al., (2007) [14] and Pereira et al., (2012) [15] who indicated that pure breeds are more susceptible to canine demodicosis than crossbreeds. Similar to present study Kuznetsova et al. (2012) [16] also recorded that the pug was more predisposed to the infection of demodectic mange.

However the present higher prevalence of the canine demodicosis in Pug and non-descript dogs could be due to their predominant representation in the study. However, a study involving wide range of breeds with more number would be required for proper conclusions to be made.

Table 4: Breed wise prevalence of canine demodicosis $(n=25)$

\begin{tabular}{|c|c|c|c|}
\hline S. No. & Name of the breed & No of dogs affected & Percentage (\%) \\
\hline 1. & Pug & 12 & 48 \\
\hline 2. & Labrador Retriever & 4 & 8 \\
\hline 3. & German shepherd & 2 & 4 \\
\hline 4. & Dachshund & 1 & 24 \\
\hline 5. & Mongrel & 6 & 100 \\
\hline
\end{tabular}

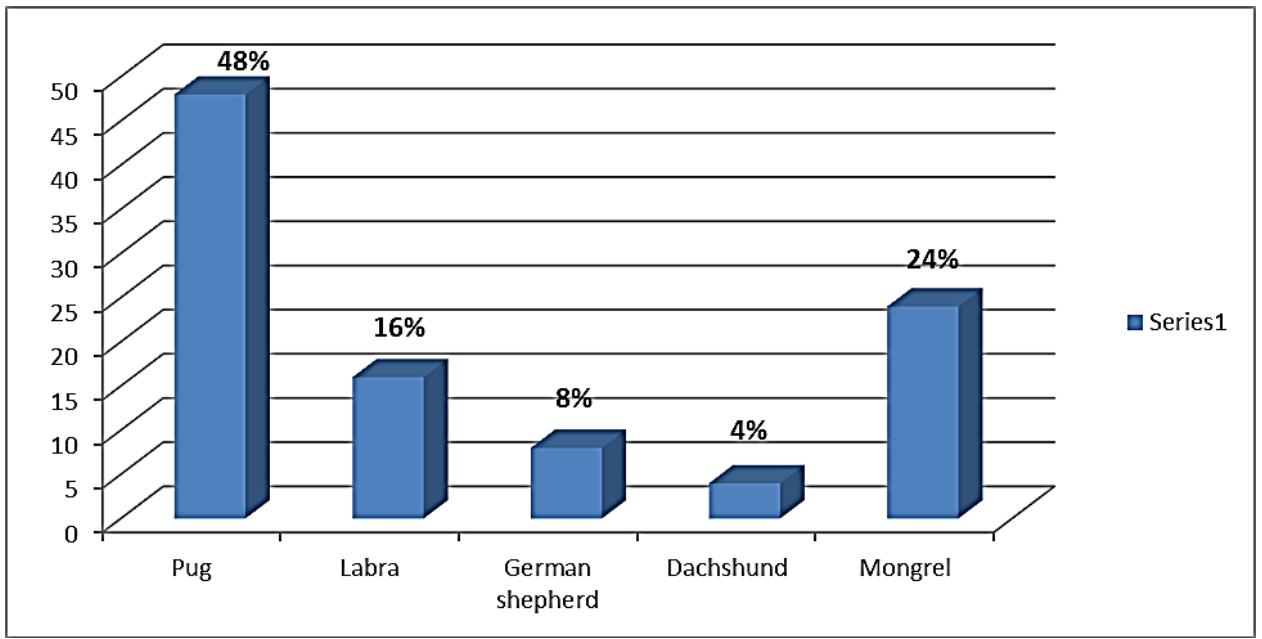

Fig 3: Breed wise prevalence of canine demodicosis $(n=25)$

\section{Clinical findings}

Out of 240 cases of dermatological problems, 25 dogs were found positive for demodex mite on skin scrapings examination. Clinical signs of these cases were recorded in the case sheet performa for dermatology. The dogs were categorized in to generalized and localized demodicosis based on the depth of lesions, extension of infection process. Cases in which presence of less than five circulars alopecic areas on body were taken in localized form and whereas presence of more than five circulars alopecic areas on body were taken in generalized demodicosis ${ }^{[17]}$.

\section{Localized and generalized canine demodicosis}

In the present study out of 25 dogs with demodicosis, 19 $(76 \%)$ were generalized form and $6(24 \%)$ were localized form. (Table 5, Figure 4), the similar findings were also reported by Pereira et al. (2012) ${ }^{[15]}$, who reported that $70 \%$ dogs had the generalised form and $30 \%$ had the localised form of demodicosis in their study and Mritunjaykumar et al. (2013) ${ }^{[18]}$ found that $20.83 \%$ dogs suffered from localized demodicosis and $79.17 \%$ with generallized demodicosis. 
Table 5: Localized and generalized canine demodicosis

\begin{tabular}{|c|c|c|c|c|}
\hline $\begin{array}{c}\text { Number of cases } \\
\text { positive for } \\
\text { demodicosis }\end{array}$ & $\begin{array}{c}\text { Number of cases positive } \\
\text { for generalized } \\
\text { demodicosis }\end{array}$ & $\begin{array}{c}\text { Percentage of } \\
\text { generalized } \\
\text { demodicosis }(\boldsymbol{\%})\end{array}$ & $\begin{array}{c}\text { Number affected with } \\
\text { localized demodicosis }\end{array}$ & $\begin{array}{c}\text { Percentage of } \\
\text { localized demodicosis } \\
(\boldsymbol{\%})\end{array}$ \\
\hline 25 & 19 & 76 & 6 & 24 \\
\hline
\end{tabular}

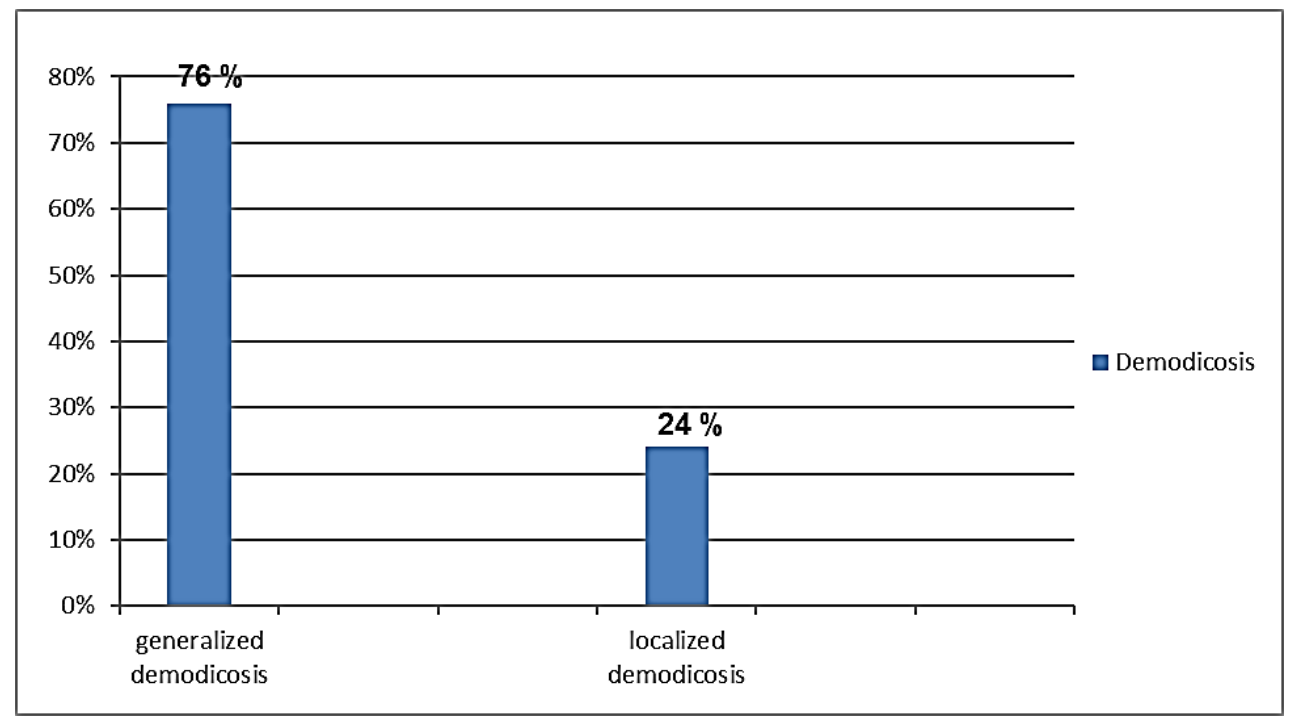

Fig 4: Percentage of Localized and generalized canine demodicosis out of total canine demodicosis cases

\section{Nature of lesion}

The dogs suffering from canine demodicosis revealed a wide variety of clinical manifestations. Clinical examination of 25 dogs with canine demodicosis revealed symptoms of alopecia in 25 dogs $(100 \%)$, scales in 15 dogs $(60 \%)$, erythema in 20 dogs $(80 \%)$, pustules in 19 dogs $(76 \%)$, pruritus in $17 \mathrm{dogs}$ (68\%), hyper pigmentation in 8 dogs (32\%), seborrheoa in 5 $\operatorname{dog}(20 \%)$, lichenification in 8 dogs $(32 \%)$, Papules in $9 \mathrm{dog}$ $(36 \%)$, and scabs in $3 \operatorname{dog}(12 \%)^{[19,20,21]}$.
Alopecia is a consistent and remarkable clinical sign exhibited by almost all the affected dogs which might be resulted due to inflammations and irritations caused by the mites in the hair follicles (Muller et al., 1989) ${ }^{[13]}$. Erythema or reddening of the skin is might be due to the inflammatory reaction occurring as a result of damage caused by epidermal cells or due to exudates produced by the infested mites in the skin or due to increased peripheral blood circulation.

Table 6: Nature of lesions seen in canine demodicosis $(n=25)$

\begin{tabular}{|c|c|c|c|}
\hline S. No. & Nature of lesion & No. of dogs affected & Percentage (\%) \\
\hline 1 & Pustules & 19 & 76 \\
\hline 2 & Scales & 15 & 80 \\
\hline 3 & Erythema & 20 & 12 \\
\hline 4 & Scabs & 3 & 32 \\
\hline 5 & Hyper pigmentation & 8 & 20 \\
\hline 6 & Seborrheoa & 25 & 100 \\
\hline 7 & Alopecia & 8 & 32 \\
\hline 8 & Lichenification & 9 & 36 \\
\hline 9 & Papules & 17 & 68 \\
\hline 10 & Pruritus & & \\
\hline
\end{tabular}

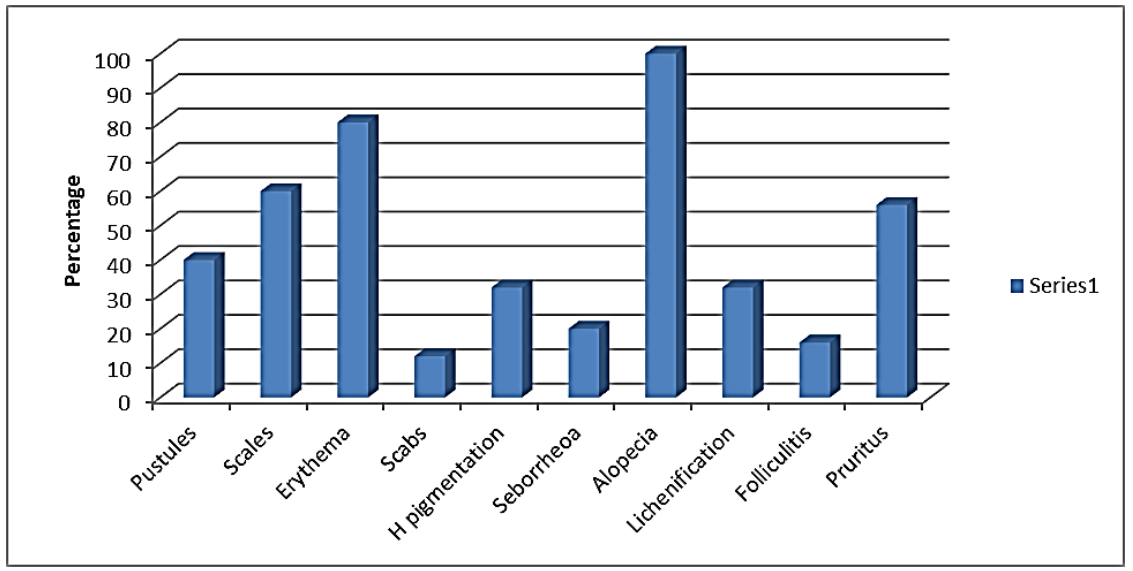

Fig 5: Histogram showing nature of lesion in canine demodicosis 


\section{Distribution of lesions}

The lesions involved in different parts of the dogs with demodicosis were recorded. In the present study, face was the primary target site in dogs affected with demodicosis, in head position periocular area $(56 \%)$, perioral $(68 \%)$, calvaria $(48 \%)$ and chin $(72 \%)$ were the primary target site in dogs affected with demodicosis followed by fore limbs (56\%), hind limbs $(44 \%)$, tail (36\%), abdomen (24\%), neck $(56 \%)$ and dorsum $(40 \%)$. These findings were similar to previous reports of Saridomichelakis et al. (2007) ${ }^{[22]}$, Boda (2016) ${ }^{[23]}$ and Janus et al. (2014) ${ }^{[8]}$.

Table 7: Distribution of lesions in canine demodicosis $(n=25)$

\begin{tabular}{|c|c|c|c|c|}
\hline S. No. & Position & Area & Number affected & Percentage (\%) \\
\hline \multirow{4}{*}{1} & \multirow{4}{*}{ Head } & Periocular & 14 & 56 \\
\hline & & Perioral & 17 & 68 \\
\hline & & Calvaria & 12 & 48 \\
\hline & & Chin & 18 & 72 \\
\hline \multirow{4}{*}{2} & \multirow{4}{*}{ Body } & Abdomen & 6 & 24 \\
\hline & & Dorsum & 10 & 40 \\
\hline & & Neck & 14 & 56 \\
\hline & & Tail & 9 & 36 \\
\hline \multirow{2}{*}{3} & \multirow[t]{2}{*}{ Limbs } & Forelimb & 14 & 56 \\
\hline & & Hind limb & 11 & 44 \\
\hline
\end{tabular}

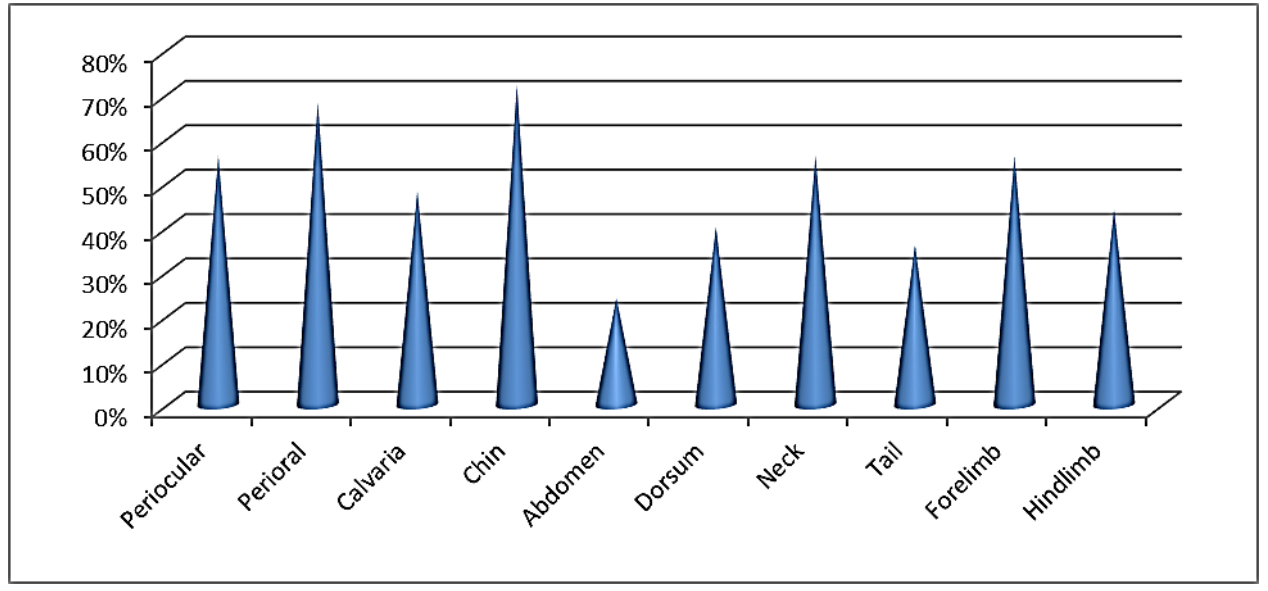

Fig 7: Pie diagram showing distribution of lesions in canine demodicosis $(\mathrm{n}=25)$

\section{Conclusion}

Based on the findings of present study, it was concluded that the prevalence of canine demodicosis among the total dogs examined with skin problems was $10.42 \%(25 / 240)$. Maximum numbers of cases were from the age group of less than 2 years. Prevalence was more common in female than male dogs.

In the present study higher prevalence of the disease was observed in Pug and Non-descript dogs.

In the present study $76 \%$ cases were generalized form and $24 \%$ cases were localized form of demodicosis.

In the present study, face was the primary target site in dogs affected with demodicosis Most common symptoms observed in canine demodicosis were mainly alopecia, erythema and pustules.

\section{Acknowledgement}

We acknowledge Department of Clinical Veterinary Medicine, Ethics and Jurisprudence, CVAS, Bikaner for providing facilities to carry out this research study.

\section{References}

1. Ferrer L, Ivan R, Silbermayr K. Immunology and pathogenesis of canine demodicosis. Veterinary Dermatology. 2014; 25:427-65.

2. Mueller RS. Treatment protocols for demodicosis: an evidence-based review. Veterinary Dermatology. 2004;
15:75-89.

3. Chen YZ, Lin RQ, Zhou DH, Song HQ, Chen F, Yuan Z et al. Prevalence of Demodex infection in pet dogs in Southern China. African Journal of Microbiology Research. 2012; 6(6):1279-1282.

4. Daga M. Clinico-Therapeutic Studies on Dermatological Disorders in Dogs., College of Veterinary and Animal Science, RAJUVAS Bikaner. MVSc Thesis, 2015.

5. Kumar A, Das AK, Sinha M, Arya SKD, Kumar A, Kumar B. Study on the Prevalence of Demodectic Mange in Dogs in and Around Patna. International Journal of Current Microbiology and Applied Sciences. 2018; 7:4216-4221.

6. Craig M. Diagnosis and management of pyoderma in the dog. In Practice. 2003; 25(7):421-425.

7. Gortel K. Update on canine demodicosis. Veterinary Clinical Small Animal Practice. 2006; 36(1):229-241.

8. Janus A, Tresamol PV, Mercey KA, Habeeb BP, Shameem H. A study on clinical and haematobiochemical parameters in canine demodicosis. Indian Journal of Canine Practice. 2014; 6:92-94.

9. Schwartzman RM, Orkin M. A Comparative Study of Skin Diseases of Dog and Man. Thomas, 1962, 492.

10. Chakraborty S. Dermatitis in dogs with special reference to demodicosis (Doctoral dissertation, Kolkata), 2012.

11. Mueller RS, Bensignor E, Ferrer L, Holm B, Lemarie S, Paradis $\mathrm{M}$ et al. Treatment of demodicosis in dogs: 
clinical practice guidelines. Veterinary Dermatology. 2011; 23:86-121.

12. Nesbitt GH. Canine and feline dermatology: A systematic approach. Lea and Febiger, Philadelphia, 1983.

13. Mullar GH, Krik RW, Scott DW. Cutaneous parasitology. In Small Animal Dermatology. W. B. Saunders Ca. Philadephial PP, 1989, 137-142.

14. Solanki JB, Hasnani JJ, Patel DM, Patel PV, Raval SK. Canine demodicosis in Anand. Journal of Veterinary Parasitology. 2007; 21(1):79-80.

15. Pereira AV, Pereira SA, Gremiao IDF, Campos MP, Ferreira AMR. Comparison of acetate tape impression with squeezing versus skin scraping for the diagnosis of canine demodicosis. Australian Veterinary Journal. 2012; 90(11).

16. Kuznetsova E, Bettenay S, Nikolaeva L, Majzoub M, Muller R. Influence of systemic antibiotics on the treatment of dogs with generalized demodicosis. Veterinary Parasitology. 2012; 188:148-155.

17. Scott DW, Miller WH, Griffin CE. Parasitic skin diseases. In Muller and Kirk,s Small Animal Dermatology. 5th Edn. W.B. Saunders, Philadelphia, 1995, 417-432.

18. Mritunjay Kumar, Roy J, Guha P, Bijwal D. Canine Demodicosis and its Therapeutic Management - A Report of 24 cases. Intas Polivet. 2013; 14(2):276-277.

19. Elsheika H, Freeman E, Madouasse SP, Flynn R. Risk factors predisposing dogs to demodicosis: a retrospective study. Veterinary Times. 2011; 40:26.

20. Prapasarakul N, Arya N, Tarnrattana C, Methiyapun S, Muaungyai M. The treatment of canine demodicosis with the oral application of ivermectin. Thailand Journal of Veterinary Medicine. 2001; 31(2):222-225.

21. Jyotsna P, Maiti SK, Sanyal PK, Tiwari SP. Haematobiochemical and mineral profiles in generalised canine demodicosis. Intas Polivet. 2005; 6(2):331-334.

22. Saridomichelakis MN, Koutinas AF, Farmaki R, Leontides LS, Kasabaiis D. Relative sensitivity of hair plucking and exudates microscopy for the diagnosis of canine demodicosis. Veterinary Dermatology. 2007; 18(2):138-141.

23. BODA S. Diagnostic and theraputic aspects of canine demodicosis. P. V. Narsimharav Telangana Veterinary University College of Veterinary Sciences, Rajendranagar, Hyderabad-30. MVSc Thesis, 2016. 